\title{
Energy Availability in Athletics: Health, Performance, and Physique
}

\author{
Anna K. Melin \\ University of Copenhagen \\ Ida A. Heikura \\ Australian Institute of Sport and Australian Catholic University \\ Adam Tenforde \\ Spaulding Rehabilitation Hospital \\ Margo Mountjoy \\ McMaster University and IOC Medical Commission-Games Group
}

\begin{abstract}
The reported prevalence of low energy availability (LEA) in female and male track and field athletes is between $18 \%$ and $58 \%$ with the highest prevalence among athletes in endurance and jump events. In male athletes, LEA may result in reduced testosterone levels and libido along with impaired training capacity. In female track and field athletes, functional hypothalamic amenorrhea as consequence of LEA has been reported among $60 \%$ of elite middle- and long-distance athletes and $23 \%$ among elite sprinters. Health concerns with functional hypothalamic amenorrhea include impaired bone health, elevated risk for bone stress injury, and cardiovascular disease. Furthermore, LEA negatively affects recovery, muscle mass, neuromuscular function, and increases the risk of injuries and illness that may affect performance negatively. LEA in track and field athletes may occur due to intentional alterations in body mass or body composition, appetite changes, time constraints, or disordered eating behavior. Long-term LEA causes metabolic and physiological adaptations to prevent further weight loss, and athletes may therefore be weight stable yet have impaired physiological function secondary to LEA. Achieving or maintaining a lower body mass or fat levels through long-term LEA may therefore result in impaired health and performance as proposed in the Relative Energy Deficiency in Sport model. Preventive educational programs and screening to identify athletes with LEA are important for early intervention to prevent long-term secondary health consequences. Treatment for athletes is primarily to increase energy availability and often requires a team approach including a sport physician, sports dietitian, physiologist, and psychologist.
\end{abstract}

Keywords: eating disorders, injury, relative energy deficiency in sports, weight loss

Track and field athletes have intense physiological demands and require optimized nutrition (Burke et al., 2019; Slater et al., 2018; Stellingwerff et al., 2018; Sygo et al., 2019). Track and field athletes may experience low energy availability (LEA) due to disordered eating (DE) behavior, inadvertently due to lack of appetite or poor nutritional knowledge, or intentionally to achieve a discipline-specific physique to optimize performance (Burke et al., 2018c; Melin et al., 2015; Mooses \& Hackney, 2017; Sygo et al., 2018). LEA may result in adverse health outcomes, increased risk of musculoskeletal injuries, and impaired athletic

Melin is with the Dept. of Nutrition, Exercise and Sports, University of Copenhagen, Frederiksberg, Denmark. Heikura is with Sports Nutrition, Australian Institute of Sport, Canberra, Australian Capital Territory, Australia; and the Mary MacKillop Institute for Health Research, Australian Catholic University, Melbourne, Victoria, Australia. Tenforde is with the Dept. of Physical Medicine and Rehabilitation, Spaulding Rehabilitation Hospital, Cambridge, MA. Mountjoy is with the Dept. of Family Medicine, McMaster University, Hamilton, Ontario, Canada; and IOC Medical Commission-Games Group, Lausanne, Switzerland. Address author correspondence to Anna K. Melin at aot@nexs.ku.dk. performance (Figure 1; De Souza et al., 2014; Mountjoy et al., 2018; Nattiv et al., 2007). The purpose of this review is to describe LEA and potential physiological and psychological consequences in the context of athletics and to provide recommendations regarding prevention, early detection, and treatment to achieve safe participation in sport for optimal health and performance.

\section{Low Energy Availability}

Energy availability (EA) reflects the difference in energy intake and exercise energy expenditure in relation to fat-free mass (FFM) (Loucks, 2014). Although studies have been unable to determine optimal EA in athletes, EA of at least $45 \mathrm{kcal} / \mathrm{kg} \mathrm{FFM} /$ day for sedentary eumenorrheic normal weight women (Loucks, 2014) and $40 \mathrm{kcal} / \mathrm{kg} \mathrm{FFM/day} \mathrm{for} \mathrm{exercising} \mathrm{men} \mathrm{(Koehler} \mathrm{et} \mathrm{al.,} \mathrm{2016)}$ appears to be a threshold to ensure optimal EA for physiological functions (Table 1). Clinical studies on eumenorrheic subjects have reported that even a short period of EA ( 5 days $)<30 \mathrm{kcal} / \mathrm{kg}$ FFM/ day causes severe endocrine and metabolic alterations (Figure 1; Ihle \& Loucks, 2004; Loucks \& Thuma, 2003). In female athletes, 


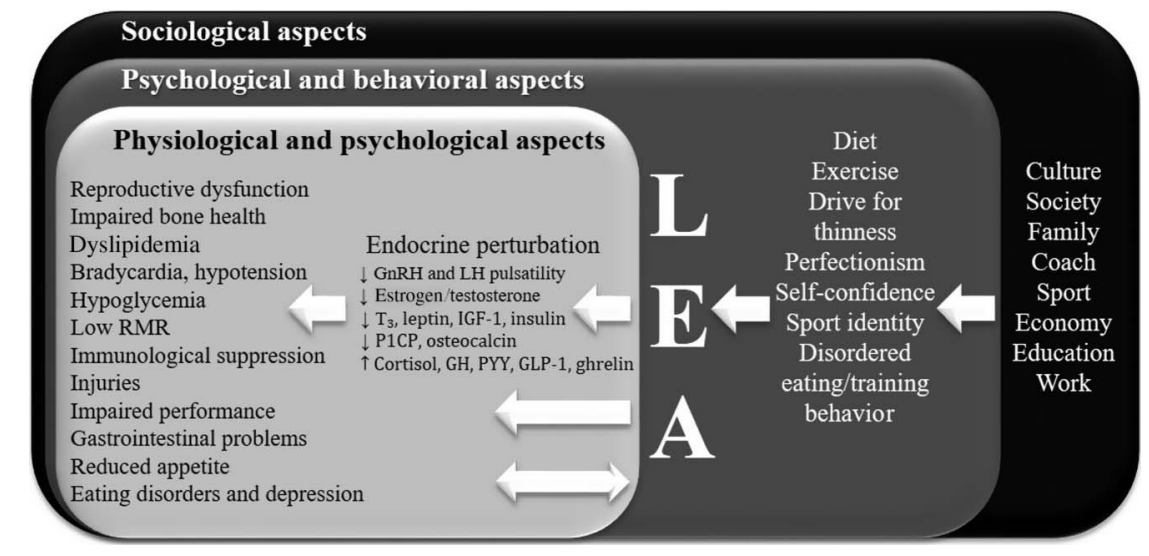

Figure 1 - Potential cause and effect diagram of LEA in athletes. The figure illustrates examples of sociological, psychological, and behavioral causes of LEA, and its potential physiological and psychological effects in athletes described in the literature (Burke et al., 2018, 2018c, De Souza et al., 2014; Elliott-Sale et al., 2018; Ihle \& Loucks, 2004; Laughlin \& Yen, 1996; Loucks, 2014; Loucks \& Thuma, 2003; Melin et al., 2015; Mountjoy et al., 2015, 2018; Nattiv et al., 2007; Rickenlund et al., 2005; Thompson et al., 1993; Tornberg et al., 2017; Turton et al., 2017). Low substrate and nutrient availability negatively affect cognitive and physical function and health as well as performance both directly and indirectly. LEA causes endocrine changes that increase the risk for reproductive and endothelial dysfunction, dyslipidemia, gastrointestinal problems, reduced appetite, injuries, impaired bone health, and immunological suppression. Gastrointestinal problems, reduced appetite, disordered eating, or compulsive exercise behavior as well as depression can precede or be caused by LEA illustrated by the double-headed arrow. GnRH = gonadotropin-releasing hormone; LEA = low energy availability; $\mathrm{LH}=$ luteinizing hormone; $\mathrm{T}_{3}=$ triiodothyronine; IGF-1 = insulin-like growth factor $1 ; \mathrm{P} 1 \mathrm{CP}=$ carboxy-terminal propeptide of Type I procollagen in serum; GH = growth hormone; PYY = peptide YY; GLP-1 = glucagon-like peptide-1; RMR = resting metabolic rate.

\section{Table 1 Classification of Energy Availability Levels With Examples of Calculation for a Hypothetical Male and} Female Athlete

\begin{tabular}{|c|c|c|c|}
\hline Energy availability & Comments & $\begin{array}{l}\text { Example 1: } \\
\text { Male athlete: } 75 \mathrm{~kg} ; 69 \mathrm{~kg} \\
\text { FFM ( } 8 \% \text { body fat) } \\
\text { Training at moderate } \\
\text { intensity } \sim 1.5-2 \text { hr/day }\end{array}$ & $\begin{array}{l}\text { Example 2: } \\
\text { Female athlete: } 60 \mathrm{~kg} ; 49 \mathrm{~kg} \\
\text { FFM (18\% body fat) } \\
\text { Training at moderate } \\
\text { intensity } \sim 1.5-2 \text { hr/day }\end{array}$ \\
\hline $\begin{array}{l}>40 \mathrm{kcal} / \mathrm{kg} \text { FFM } \\
\text { (males) } \\
>45 \mathrm{kcal} / \mathrm{kg} \text { FFM } \\
\text { (females) }\end{array}$ & $\begin{array}{l}\text { High EA: } \\
\text { For healthy weight gain or weight } \\
\text { maintenance }\end{array}$ & $\begin{array}{l}\mathrm{EEE}=1,500 \mathrm{kcal} / \mathrm{day} \\
\mathrm{EI}=\mathbf{4 , 6 0 0} \mathbf{~ k c a l} / \text { day } \\
\mathrm{EA}=(4,600-1,500) / 69=45 \mathrm{kcal} / \mathrm{kg} \\
\mathrm{FFM} / \text { day }\end{array}$ & $\begin{array}{l}\mathrm{EEE}=1,000 \mathrm{kcal} / \mathrm{day} \\
\mathrm{EI}=\mathbf{3 , 5 0 0} \mathbf{~ k c a l} / \mathbf{d a y} \\
\mathrm{EA}=(3,500-1,000) / 49=51 \mathrm{kcal} / \mathrm{kg} \\
\mathrm{FFM} / \text { day }\end{array}$ \\
\hline $\begin{array}{l}\geq 40 \mathrm{kcal} / \mathrm{kg} \text { FFM } \\
\text { (males) } \\
\geq 45 \mathrm{kcal} / \mathrm{kg} \mathrm{FFM} \\
\text { (females) }\end{array}$ & $\begin{array}{l}\text { Optimal EA: } \\
\text { For weight maintenance providing } \\
\text { adequate energy for all physiological } \\
\text { functions. } \\
\text { During periods with injury with alter- } \\
\text { native or rehabilitation training at } \\
\text { low/moderate intensity } \sim 1.5 \mathrm{hr} / \text { day }\end{array}$ & $\begin{array}{l}\mathrm{EEE}=1,500 \mathrm{kcal} / \mathrm{day} \\
\mathrm{EI}=\mathbf{4 , 2 5 0} \mathbf{~ k c a l} / \text { day } \\
\mathrm{EA}=(4,250-1,500) / 69=40 \mathrm{kcal} / \mathrm{kg} \\
\mathrm{FFM} / \mathrm{day} \\
\mathrm{EEE}=750 \mathrm{kcal} / \mathrm{day} \\
\mathrm{EI}=\mathbf{3 , 5 0 0} \mathbf{~ k c a l} / \text { day } \\
\mathrm{EA}=(3,500-750) / 69=40 \mathrm{kcal} / \mathrm{kg} \\
\mathrm{FFM} / \text { day }\end{array}$ & $\begin{array}{l}\mathrm{EEE}=1,000 \mathrm{kcal} / \mathrm{day} \\
\mathrm{EI}=\mathbf{3 , 2 0 0} \mathbf{k c a l} / \text { day } \\
\mathrm{EA}=(3,200-1,000) / 49=45 \mathrm{kcal} / \mathrm{kg} \\
\mathrm{FFM} / \mathrm{day} \\
\mathrm{EEE}=500 \mathrm{kcal} / \mathrm{day} \\
\mathrm{EI}=\mathbf{2 , 7 0 0} \mathbf{~ k c a l} / \mathbf{d a y} \\
\mathrm{EA}=(2,700-500) / 49=45 \mathrm{kcal} / \mathrm{kg} \\
\mathrm{FFM} / \text { day }\end{array}$ \\
\hline $\begin{array}{l}\text { 30-40 kcal/kg FFM } \\
\text { (males) } \\
30-45 \mathrm{kcal} / \mathrm{kg} \text { FFM } \\
\text { (females) }\end{array}$ & $\begin{array}{l}\text { Subclinical LEA: } \\
\text { May be tolerated for short periods during } \\
\text { a well-constructed weight-loss program }\end{array}$ & $\begin{array}{l}\mathrm{EEE}=1,500 \mathrm{kcal} / \text { day } \\
\mathrm{EI}=\mathbf{4 , 0 0 0} \mathbf{k c a l} / \text { day } \\
\mathrm{EA}=(4,000-1,500) / 69=36 \mathrm{kcal} / \mathrm{kg} \\
\mathrm{FFM} / \text { day }\end{array}$ & $\begin{array}{l}\mathrm{EEE}=1,000 \mathrm{kcal} / \mathrm{day} \\
\mathrm{EI}=\mathbf{2 , 7 0 0} \mathbf{k c a l} / \mathrm{day} \\
\mathrm{EA}=(2,700-1,000) / 49=35 \mathrm{kcal} / \mathrm{kg} \\
\mathrm{FFM} / \text { day }\end{array}$ \\
\hline$<30 \mathrm{kcal} / \mathrm{kg}$ FFM & $\begin{array}{l}\text { Clinical LEA: } \\
\text { Health implications with impairment of } \\
\text { many body systems including training } \\
\text { adaptation and performance }\end{array}$ & $\begin{array}{l}\mathrm{EEE}=1,500 \mathrm{kcal} / \mathrm{day} \\
\mathrm{EI}=\mathbf{3 , 5 0 0} \mathbf{~ k c a l} / \mathbf{d a y} \\
\mathrm{EA}=(3,500-1,500) / 69=29 \mathrm{kcal} / \mathrm{kg} \\
\mathrm{FFM} / \text { day }\end{array}$ & $\begin{array}{l}\mathrm{EEE}=1,000 \mathrm{kcal} / \mathrm{day} \\
\mathrm{EI}=\mathbf{2 , 3 0 0} \mathbf{k c a l} / \text { day } \\
\mathrm{EA}=(2,300-1,000) / 49=27 \mathrm{kcal} / \mathrm{kg} \\
\mathrm{FFM} / \text { day }\end{array}$ \\
\hline
\end{tabular}

Note. All numbers regarding EI are in bold. EA = energy availability; EEE = exercise energy expenditure; EI = energy intake; LEA = low energy availability; FFM = fatfree mass.

EA $<30 \mathrm{kcal} / \mathrm{kg} \mathrm{FFM} /$ day is typically defined as clinical LEA and EA between 30 and $45 \mathrm{kcal} / \mathrm{kg}$ FFM/day as subclinical LEA (Table 1; De Souza et al., 2014; Melin et al., 2015). However, studies on free-living athletes have failed to find clear thresholds or associations between EA and objective measures of energy conservation or health impairment, such as disruption to metabolic hormones (Heikura et al., 2018; Koehler et al., 2013) and menstrual dysfunction (Melin et al., 2015; Williams et al., 2015). Initially, 
LEA leads to a negative energy balance and thereby weight loss because the body's energy reserves (e.g., adipose tissue and body proteins) substantially contribute to fuel needs. However, longterm LEA causes metabolic and physiological adaptations in order to reduce total energy expenditure to prevent further weight loss and promote survival, whereby the body obtains a new energy balance steady state (Loucks, 2014). Therefore, an athlete may be weight stable and not excessively low in body mass or body fat levels yet have impaired physiological function secondary to LEA (Burke et al., 2018c; Loucks, 2014).

Athletics consists of a wide array of disciplines that vary significantly in physiological requirements, training characteristics, and optimal physique (Table 2; Burke et al., 2019; Slater et al., 2018; Stellingwerff et al., 2018; Sygo et al., 2019). Middle- and long-distance athletes tend to be small and lean; high jumpers are usually tall and lean; and power athletes (sprints, long and triple jump, pole vault, heptathlon, and decathlon) are both lean and more muscular and powerful. In contrast, throwers tend to be larger with higher adiposity.

The mismatch between energy intake and exercise energy expenditure that causes LEA in athletes may occur intentionally in order to optimize body mass or body composition for competition, to avoid weight gain during injury and illness or due to eating disorders (EDs) or DE behavior. Several potential reasons may explain inadvertent LEA such as large energy needs and suppressed appetite during periods of high-intensity training, especially when combined with adherence to ultrahealthy or "clean" eating with low energy density diets (Burke et al., 2018c; Melin et al., 2016). Energy intake may be suboptimal due to other factors including lack of financial or time resources as well as cultural beliefs (Burke et al., 2018). Dietary aspects other than LEA may also affect physiological function such as extreme dietary fiber intake (Melin et al., 2016) and suboptimal within-day energy balance. Recent studies reported that despite similar 24-hr EA and energy balance, female endurance athletes with functional hypothalamic amenorrhea (FHA) spent more time in a catabolic state compared with eumenorrheic athletes (Fahrenholtz et al., 2018) and demonstrate increased catabolic markers in male endurance athletes (Torstveit et al., 2018).

\section{Prevalence of LEA, DE, and EDs in Athletics}

Underreporting or undereating are well-documented behaviors during prospective dietary recording and can therefore explain some of the discrepancies between reported energy intakes and energy needs in athletes and hence result in a potentially false positive diagnosis of LEA (Burke et al., 2018c). The high prevalence of EDs/DE and physiological symptoms of LEA such as oligomenorrhea or FHA in women and low testosterone in men indicates, however, that many athletes are failing to balance energy expenditure with adequate energy intake (Figure 1; Mountjoy et al., 2018; Nattiv et al., 2007).

In athletics, there is a high prevalence of LEA and EDs/DE in middle- and long-distance running and jumping events and is more common in female than male athletes (Table 2; Sundgot-Borgen \& Torstveit, 2004). Studies in runners have reported similar or lower daily energy intake compared with nonathlete populations, especially in women (Laughlin \& Yen, 1996; Pettersson et al., 1999). A study investigating EA in female and male athletes from a mix of sports reported clinical LEA in $58 \%$ of male endurance athletes $(n=22)$ compared with $51 \%$ of female endurance athletes $(n=18)$ (Koehler et al., 2013). In elite athletics, the prevalence of clinical
LEA was $31 \%$ and $25 \%$ in female and male middle- and longdistance athletes, respectively (Heikura et al., 2018). Among young American collegiate female Division I track and field athletes (19.5 \pm 1.8 years), 52\% were identified with clinical LEA (Day et al., 2015), while Muia et al. (2016) reported clinical LEA in $18 \%$ of adolescent female elite Kenyan runners, compared with $2 \%$ among nonathletes. Melin et al. (2015) reported clinical LEA in $20 \%$ of elite female distance athletes, and $25 \%$ were clinically diagnosed with EDs. These results are consistent with an earlier report by SundgotBorgen and Torstveit (2004), who reported a 24\% prevalence of EDs in female national team endurance athletes compared with $9 \%$ among male endurance athletes. In contrast to running events, literature on the prevalence of LEA with and without EDs/DE in sprint and jumping events is less well characterized (Table 2; Sygo et al., 2018). Sundgot-Borgen and Torstveit (2004) reported a prevalence of EDs in $3 \%$ and $6 \%$ of male and female national team athletes in sprint and throwing events, respectively. In contrast, the prevalence of EDs in middle- and long-distance running and jumping events were $22 \%$ among male athletes and $10 \%$ in female athletes. In a study by Hausenblas and McNally (2004) investigating the prevalence of DE in track and field athletes versus nonathletes with higher or lower activity levels, the prevalence was higher in females $(14 \%)$ compared with males $(4 \%)$, and in nonathletes with a higher activity level (14\%) compared with athletes $(7 \%)$ and nonathletes (8\%) with low activity levels. Discipline-based division showed DE in $12 \%$ of the middle- and long-distance runners, $5 \%$ of the sprint athletes, and $0 \%$ of the field athletes (Hausenblas \& McNally, 2004).

While LEA and associated health conditions are observed in adult track and field athletes, there is compelling evidence that LEA with and without DE may start during youth (De Souza et al., 2014; Nattiv et al., 2007). In a study investigating EA in female high school athletes $(n=80)$ including track athletes $(n=24)$ and sedentary controls $(n=80)$, similar prevalence of subclinical LEA among athletes $(31 \%)$ and controls (39\%) was reported (Hoch et al., 2009). Early attitudes on ideal body type and DE have been reported in high school runners. While $<2 \%$ of the 748 runners surveyed reported DE, over $23 \%$ of girls and $8 \%$ of boys reported dieting or skipping meals to lose weight (Tenforde et al., 2011). A separate report of a subset of this sample identified the belief that "being thinner leads to faster running performances" in over half of the girls and two thirds of the boys (Tenforde et al., 2015).

\section{Outcomes of LEA}

The Relative Energy Deficiency in Sport (RED-S) model describes 10 health outcomes and 10 potential performance effects resulting from LEA in athletes (Mountjoy et al., 2018). A summary of the current knowledge of health and performance impairments related to LEA is reported and discussed in detail in the International Olympic Committee Consensus Statement for RED-S (Mountjoy et al., 2018). In the following section, studies relevant to the reporting of LEA and related conditions in athletics will be presented.

\section{Reproductive Dysfunction}

Reduced sex hormones and associated reduced fertility may result from LEA in athletes of both sexes. LEA in female athletes may result in suppressed sex hormones and FHA, a neuroendocrine condition diagnosed by excluding alternative etiology (Gordon et al., 2017). The prevalence of FHA appears to be high in running 


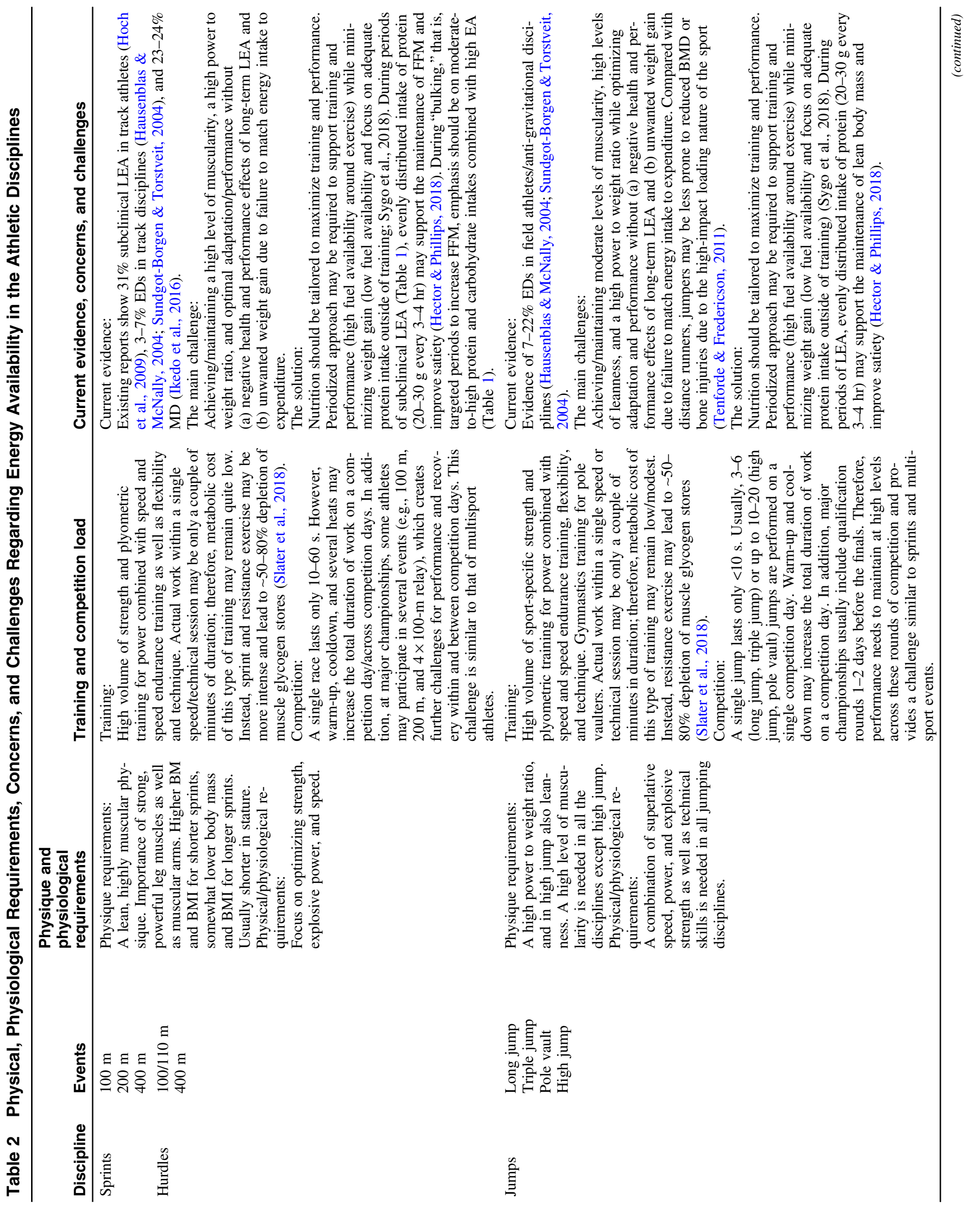




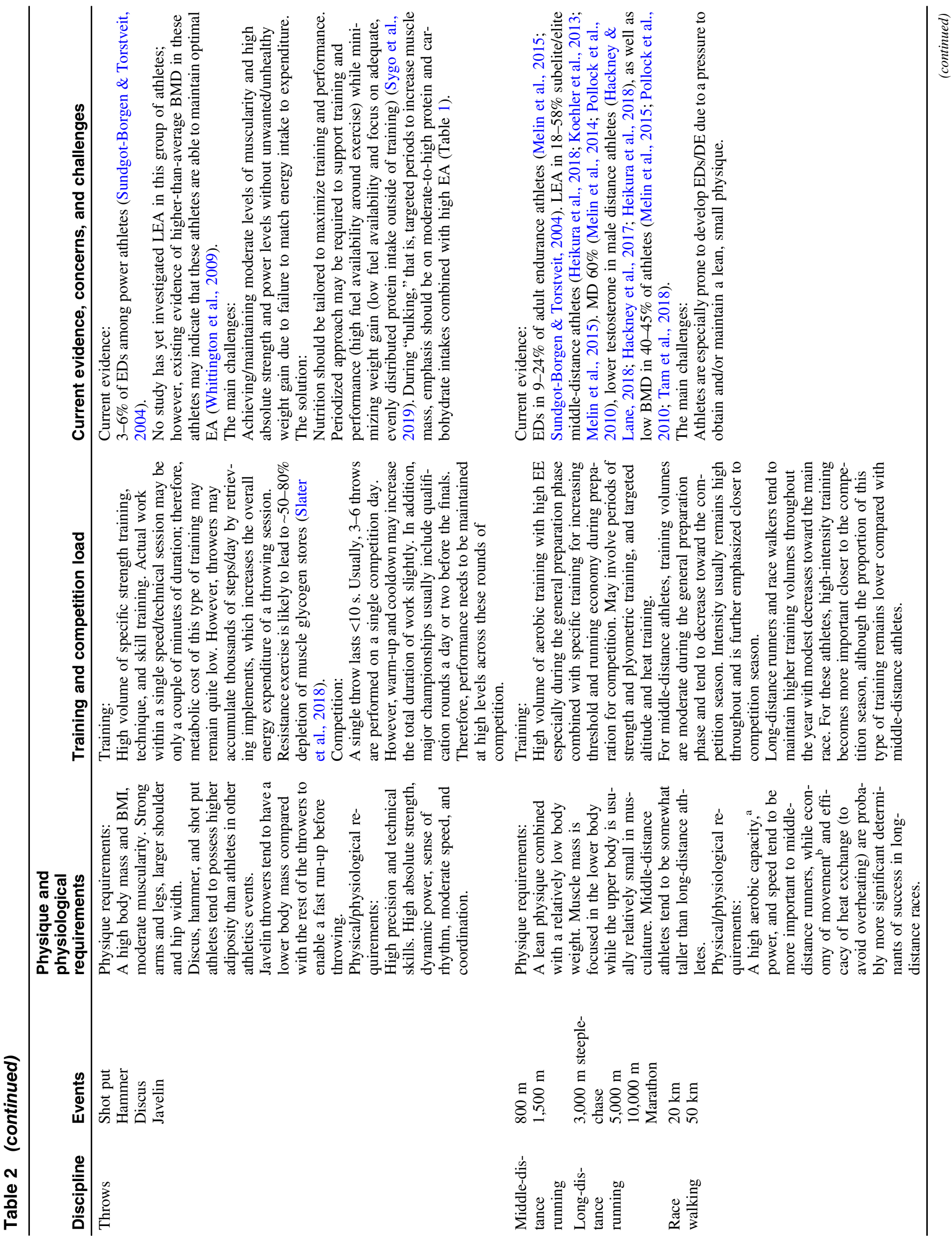




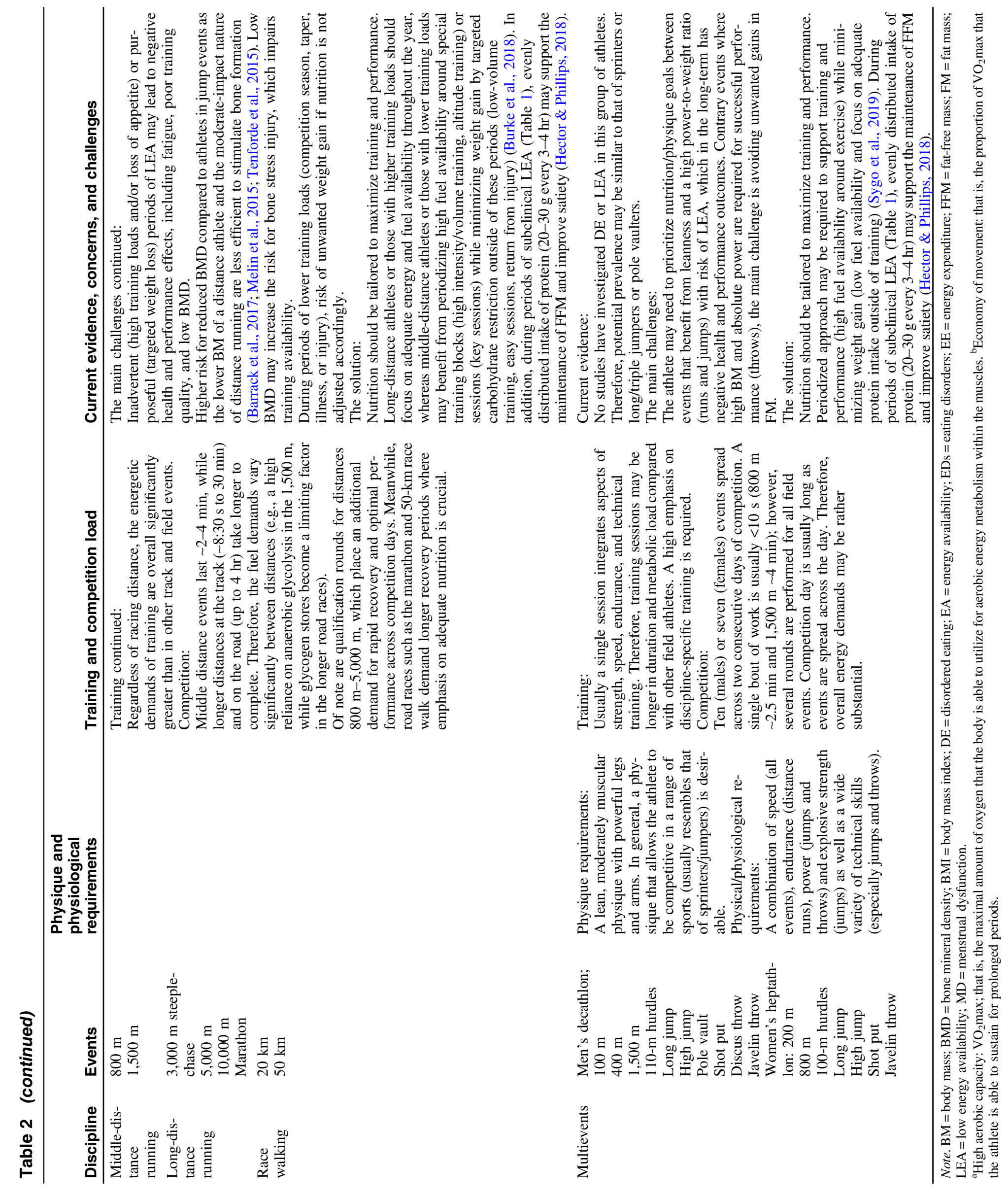


events. Self-reported menstrual dysfunction was observed in $60 \%$ of English elite middle- and long-distance runners (Pollock et al., 2010) similar to results observed in Swedish and Danish middleand long-distance athletes with $60 \%$ clinically verified FHA (Melin et al., 2015). Among young track and field athletes, $40 \%$ reported menstrual dysfunction (Day et al., 2015). In contrast, elite and adolescent sprinters have a reported prevalence of $23-24 \%$ selfreported menstrual dysfunction (Ikedo et al., 2016; Sygo et al., 2018). Polycystic ovarian syndrome is common in the general population and phenotypes such as coexistence of FHA and has been reported (Gordon et al., 2017). To ensure correct diagnosis and treatment, a thorough clinical evaluation of the causes of menstrual dysfunction is recommended (Gordon et al., 2017). Health concerns with FHA include impaired bone mineral density (BMD), elevated risk for bone stress injury (BSI), impaired fertility, and increased cardiovascular risk factors (De Souza et al., 2014; Mountjoy et al., 2018; Nattiv et al., 2007).

A recent review concluded that the specific neuroendocrine changes from LEA are not as well understood in male athletes (Elliott-Sale et al., 2018). While the mechanism is inconclusive, male athletes appear to be at risk for lower testosterone levels and associated symptoms of hypogonadal state. A cross-sectional investigation in middle- and long-distance runners and race walkers reported reduced testosterone levels in males with clinical LEA (Heikura et al., 2018). Endurance training intensity and duration are both negatively associated with libido (Hackney et al., 2017), and a $30 \%$ reduction in testosterone levels has been reported in athletes with at least 5 years of endurance running compared with athletes with fewer years of training (Hackney \& Lane, 2018). The reproductive changes associated with lowered testosterone levels have potential health implications relative to fertility, bone health, and metabolic function in men (Hackney \& Lane, 2018).

\section{Impaired Skeletal Health and BSI}

Bone mineral density $Z$ score $<-1.0$ has been proposed as low BMD for both female and male athletes participating in land-based sports (Barrack et al., 2017; Mountjoy et al., 2015; Nattiv et al., 2007). Risk factors for low BMD identified in female runners include prolonged distance running, lower BMI, menstrual dysfunction, history of BSI, and lower FFM (Barrack et al., 2017; Tenforde et al., 2015). Similarly, male runners with low BMI believe that being thinner leads to faster running performances, and athletes running greater than 30 miles $(48 \mathrm{~km})$ per week are at an elevated risk for impaired skeletal health (Barrack et al., 2017; Tenforde et al., 2015). Compared with other disciplines or healthy controls, distance runners may have lower BMD at lumbar spine but higher BMD at weight-bearing sites (Bennell et al., 1997; Tam et al., 2018). Race differences in BMD values between disciplines are poorly characterized. While individuals of African descent usually have higher average bone mass than whites, one study reported that $40 \%$ of adolescent Kenyan runners measured alarmingly low spine ( nonweight-bearing site) $Z$ scores of $<-2.0 S D$ (Tam et al., 2018). Studies in adolescent female runners have reported nearly $40 \%$ prevalence of low BMD (Barrack et al., 2008) and 43-45\% in female distance athletes (Melin et al., 2015; Pollock et al., 2010). In contrast, male decathletes (Maïmoun et al., 2008); throwers (Whittington et al., 2009); and power athletes (sprinters, jumpers, and decathletes) (Bennell et al., 1997) have been reported to have higher BMD than healthy controls.

Bone stress injury, often referred to as stress fractures or stress reactions, are overuse injuries common in athletics. Recovery from
BSI may be related to and further complicated by the presence of menstrual dysfunction, EDs/DE, and low BMD referred to as Female Athlete Triad risk factors (Nattiv et al., 2013). In an early study by Marcus et al. (1985) investigating menstrual function and bone health in elite female distance runners and controls, BSI was more frequent in amenorrheic versus eumenorrheic women, and Bennell (1997) reported an annual BSI incidence of $21 \%$ in elite track and field athletes; no difference by sex was identified. Additional studies in high school runners support similar incidence of BSI by sex (Tenforde et al., 2013). Among young female Division 1 track and field athletes, 32\% reported having a history of one or more stress fractures (Day et al., 2015).

Using the Female Athlete Triad Cumulative Risk Assessment, collegiate runners categorized as having a moderate or high risk of the Triad had 4.0- and 5.7-fold risk for sustaining a BSI compared with athletes categorized as having low risk; a majority of runners in the elevated risk category sustained a BSI within average of 1 year (Tenforde et al., 2017). In a recent study, Heikura et al. (2018) reported on EA status, blood hormone concentrations, bone scans, and BSI history in a group of 24 elite male middle- and longdistance athletes. Despite no differences in BMD, groups with testosterone within the lowest quartile of laboratory reference range and LEA had a 4.5- and 7.5-fold higher frequency of career BSI compared with healthy counterparts, respectively.

\section{Metabolic Alterations}

Low energy availability has been associated with decreased resting metabolic rate (RMR) in both female (Melin et al., 2014) and male middle- and long-distance athletes (Thompson et al., 1993) compared with athletes with adequate energy intake. In a clinical study in eumenorrheic women, Loucks and Verdun (1998) showed a $22 \%$ reduction in triiodothyronine $\left(\mathrm{T}_{3}\right)$ after 5 days with clinical LEA. A cross-sectional investigation in track and field athletes found that menstrual dysfunction in women and lower testosterone levels in men were associated with lower $\mathrm{T}_{3}$ (Heikura et al., 2018), supporting earlier findings of lowered $\mathrm{T}_{3}$ levels (Marcus et al., 1985; Melin et al., 2015) and RMR (Melin et al., 2015) in FHA compared with eumenorrheic elite endurance athletes. Although the suspected underlying etiology of lowered RMR and $T_{3}$ is LEA (Figure 1), further research is needed.

Other physiological consequences of LEA have been reported. Endothelial dysfunction and an unfavorable lipid profile have been reported in distance runners with FHA (Rickenlund et al., 2005), with a potential negative effect on long-term cardiovascular health. Gastrointestinal problems are commonly reported in endurance athletes, and the association of LEA and gastrointestinal problems has been reported in elite female distance athletes (Melin et al., 2014). The immune system may be altered by LEA, although the scientific evidence is scarce. One study reported more upper respiratory symptoms and lower immunoglobulin-A secretion rates in FHA versus eumenorrheic elite collegiate runners (Shimizu et al., 2012). In a study of female elite athletes in preparation for the 2016 Rio Olympic Games, indication of LEA was the leading variable associated with illnesses (Drew et al., 2017).

\section{Psychological}

As previously described, various aspects of psychological wellbeing and psychological problems such as EDs/DE can precede or be caused by LEA (Figure 1). Screening and addressing LEA and mental health risk among athletes such as perfectionism, athletic 
identity, compulsive exercise, social or sport specific weight pressure, injuries, or teammates with known EDs/DE are recommended (Hinton \& Kubas, 2005; Mountjoy et al., 2018; Turton et al., 2017).

\section{Performance}

It has been suggested that long-term LEA could negatively affect sport performance through indirect mechanisms, such as reduced recovery and impairment of optimal muscle mass and function (Mountjoy et al., 2018; Nattiv et al., 2007). Since LEA increases the risk of injury and illness, performance may be impaired due to the loss of training (Drew et al., 2017). Van Heest et al. (2014) reported a $9.8 \%$ decline in 400 -m swim velocity during a 12 -week competitive season in young elite in swimmers with chronic ovarian suppression and metabolic and hormonal perturbation secondary to energy deficiency, in contrast to an $8.2 \%$ improvement in eumenorrheic swimmers. Few studies, however, have investigated the impact of LEA on performance, and no studies to date have been performed in primary sport of athletics. A greater power to mass ratio is often regarded as important for running performance (Table 2); however, despite lower body weight and fat mass in elite amenorrheic endurance athletes, Tornberg et al. (2017) found no improved aerobic capacity compared with eumenorrheic athletes. Furthermore, FHA athletes had decreased neuromuscular performance measured as knee muscular strength and endurance and reaction time compared with the eumenorrheic athletes, and lower neuromuscular performance was associated with higher cortisol levels, and lower blood glucose, $\mathrm{T}_{3}$, estrogen, and FFM in the tested leg. These results suggest that achieving or maintaining a lower body weight through long-term LEA is likely to negatively affect performance and health (Tornberg et al., 2017), a finding supported by results from a study of East African runners (Mooses \& Hackney, 2017).

The potential negative effects of LEA and associated conditions on sport performance, and the lack of evidence regarding EA in athletic disciplines such as jumps and sprints, especially in male athletes, clearly indicate the need for more research in this area.

\section{Manipulation of Weight and Body Mass}

Similar to the yearly periodization of training, nutrition may need to be periodized to best support adaptation and performance (Stellingwerff, 2018). Although optimal EA is crucial for health and performance, periods of subclinical LEA may be necessary to reach the desired physique goals (Tables 1 and 2). Notably any effort by an athlete to target a specific physique for performance in athletic disciplines needs to account for physiological demands to ensure this does not compromise health and performance (Mountjoy et al., 2018; Tornberg et al., 2017).

Scientific evidence of successful periodization of nutrition and physique in athletics is rare. A recent case study by Stellingwerff (2018) is the first to provide insights into a career-long nutrition and body composition periodization of an Olympic female middle distance runner. For this athlete, optimal EA and weight stability with a slightly higher body weight $(\sim 2.1 \%)$ and body fat percentage during the general preparation phase compared with the competition season were emphasized. The competition season (May to August) was targeted to reach optimal body composition and race weight and included an individualized time line (6-8 weeks) with moderate caloric restriction $(-300 \mathrm{kcal} /$ day) together with adequate protein intake (2.0-2.5 g/kg/day); reduced intake of snacks; energy-dense (sweets, fats); and carbohydrate-rich foods on easy training days. Notable to this case is attainment of optimal physique at peak times without sacrificing long-term hormonal and bone health (Stellingwerff, 2018).

Evidence-based studies are required to understand strategies to achieve a specific physique while maintaining health of the athlete. Available evidence to date is presented, but these studies should be interpreted cautiously when applied to an individual athlete. Studies in leaner athletes (jumpers, sprinters, and middle- and longdistance athletes) suggest a gradual weight loss rate of $0.5-1 \%$ per week to preserve FFM (Garthe et al., 2011; Huovinen et al., 2015), sex hormones and reproductive function (Huovinen et al., 2015; Williams et al., 2015), RMR (Trexler et al., 2014), and cortisol (Huovinen et al., 2015). Regardless of event, weight loss should be carefully planned and time limited in the months preceding the competition season, with a diet and training regime provided by professional counseling ensuring subclinical LEA to reduce risk for adverse performance outcomes (Table 2). Weight manipulation among young athletes may delay pubertal development, growth, and bone accrual as well as increase risk of developing EDs/DE (De Souza et al., 2014; Mountjoy et al., 2018; Nattiv et al., 2007). Therefore, body weight manipulation for athletes younger than 18 years should be avoided.

Periodization of EA across days or weeks and within day may be useful weight-loss strategies because periodic increases in EA theoretically counteract adaptive thermogenesis, enabling further weight loss (Trexler et al., 2014), although contrary findings exist (Sundfør et al., 2018). Studies in female and male athletes showed that despite similar daily energy balance or EA, larger within-day energy deficits were associated with suppressed reproductive hormones and menstrual dysfunction (Fahrenholtz et al., 2018), lower RMR, and higher cortisol levels (Fahrenholtz et al., 2018; Torstveit et al., 2018). Therefore, during weight loss, careful timing of energy and fuel availability around training might be a useful strategy to combat metabolic stress associated with inadequate fuel supply to the muscles and the brain.

The macronutrient composition of the diet is important to consider for optimal nutrition support to physiological function and performance. Indeed, low carbohydrate availability has been linked to reduced performance (Burke et al., 2017) and lower levels of luteinizing hormone, $\mathrm{T}_{3}$, and leptin (Loucks \& Thuma, 2003). Therefore, to maintain lean body mass (Hector \& Phillips, 2018) and RMR (Trexler et al., 2014) during periods of energy restriction, adequate carbohydrate availability and protein intake (1.6-2.4 g protein/kg/day) should be encouraged.

\section{Clinical Application}

\section{Screening}

Universal screening is recommended across athletics events especially for those who participate in middle- and long-distance events or jumping events. Regardless of event, the early identification of LEA and associated health issues is essential to guide intervention and prevent long-term secondary health consequences. Therefore, screening is recommended in all athletes who might experience pressure to lose weight or fat mass, are injured, or have teammates with diagnosed EDs/DE (Mountjoy et al., 2018). Although LEA is useful in conceptualizing the development of impairments of physiological function, field assessment or screening of true EA is timeconsuming and may be subject to methodological errors associated with assessing energy intake, exercise energy expenditure, and 
FFM, even when using the best techniques available to the practitioner. When screening for LEA athletes identified as being at risk due to restricted eating behavior, lowered RMR, stress fractures, reoccurring injuries or illness, self-reported menstrual dysfunction or reduced libido needs a more thorough clinical examination and detailed assessment of EA (Burke et al., 2018c; Mountjoy et al., 2018).

Several tools are available to assist in the screening for RED-S. No screening tool has been specifically designed for the sport of athletics. One of the most practical and commonly utilized tools is the preparticipation examination that can screen athletes for early signs and symptoms of RED-S (Ljungqvist et al., 2009). A more specific screening tool for RED-S which can be incorporated into yearly screening is the LEA in Females Questionnaire (LEAF-Q), which has been developed to identify female athletes at risk for long-term LEA (Melin et al., 2014). The LEAF-Q validated in adult elite female endurance athletes, is constructed to identify physiological symptoms of LEA, and it is recommended to also include a validated DE questionnaire during screening (Melin et al., 2014). In a study combining the LEAF-Q with the Female Athlete Screening Tool (McNulty et al., 2001), 44.1\% of long-distance runners were categorized being at risk while $32.0 \%$ had DE (Folscher et al., 2015). In addition, the International Olympic Committee developed the RED-S Clinical Assessment Tool to assist clinicians with the screening and return to play of athletes at risk (Mountjoy et al., 2015), although validation of the RED-S Clinical Assessment Tool is required.

Although LEA may occur in the absence of EDs/DE (Melin et al., 2015), LEA may be caused by or further compounded by presence of EDs/DE. In athletics, this may be more common in middle- and long-distance running and jumping events where leanness and/or a low body mass is desirable. An elevated Drive for Thinness score on the Eating Disorder Inventory may also be a marker for LEA (Gibbs et al., 2011). In addition, validated screening tools exist for identifying EDs/DE in the athletic population, although these were developed prior to release of the Diagnostic and Statistical Manual-5 (Hinton \& Kubas, 2005; McNulty et al., 2001). Underreporting of self-reported eating pathology symptoms is common (Torstveit et al., 2008) and may relate to the stigma around EDs. Therefore, clinical interviews are required in addition to the self-report screening tools to confirm and differentiate the diagnosis (Melin et al., 2015; Sundgot-Borgen \& Torstveit, 2004). As athletes with EDs often have psychological comorbidities such as depression, anxiety, and substance abuse (Giel et al., 2016), and excessive or compulsive exercise often plays a causal role in the development of DE (Hinton \& Kubas, 2005; Turton et al., 2017), validated screening tools to identify other psychiatric comorbidities can also be considered as appropriate to ensure optimal treatment of the athlete.

\section{Prevention}

Prevention of LEA is focused on nonpharmacological strategies to optimize nutrition and EA. Professional nutritional counseling to track and field athletes focusing on optimal energy and nutrient availability to support periodized training, competitions, specific physical requirements and to prevent injury and illness is recommended (Melin et al., 2016; Sygo et al., 2019). Any athlete seeking to intentionally modify body composition including weight loss should be provided with professional counseling, ensuring a timelimited nutritional treatment plan with safe and effective guidelines that ends with reestablishing adequate EA and weight stability
(Melin et al., 2016). Injured athletes should be encouraged to maintain optimal EA for optimal rehabilitation (Table 2; Tipton, 2015).

Prevention initiatives also revolve around education programs focusing on athletes, coaches, and other members of the entourage. A survey of International Federations identified a lack of prevention programs on RED-S in 26 out of 28 Olympic International Federations, indicating the need for education of sport leaders and elite team physicians in the health and performance consequences of RED-S (Mountjoy et al., 2018). Although no specific RED-S prevention programs have been developed or evaluated, there are effective prevention programs for EDs in the athlete population. These include peer led (Becker et al., 2012) and school-based initiatives (Martinsen et al., 2014a) suggesting that successful EDs prevention programs should include sectors outside the domain of sport.

\section{Treatment}

The reversal of the energy deficit to achieve optimal EA has been shown to be efficacious in reversing the secondary effects of LEA to the hypothalamic-pituitary-gonadal axis and other body systems in female athletes (Cialdella-Kam et al., 2014). Athletes and coaches require education that the resumption of menstrual function occurs over months and improvement in BMD takes longer (Cialdella-Kam et al., 2014). Nutritional intervention should address not only the quantity of energy intake, but also the timing of food intake around exercise and food choices to maximize micro- and macronutrient availability (Melin et al., 2016; Sygo et al., 2019). The treatment often requires a collaborative team approach including a sport medicine physician, a trained sports dietitian, and a sport physiologist experienced in safe body composition management. If EDs/DE is part of the clinical presentation, inclusion of psychologist specialized in EDs/DE in athletes on the treatment team is also required.

The utilization of the combined oral contraceptive pill for the treatment of low BMD is not recommended, as this does not achieve clear goal of reduced stress fracture risk or improved bone health in athletes (Cobb et al., 2007). Importantly, the combined oral contraceptive pill masks FHA and thus may contribute to delayed treatment of LEA. Should the resumption of menstrual function not occur with an adequate trial of nonpharmacological interventions identified above, the use of transdermal estradiol with cyclic oral progestin can be considered (Gordon et al., 2017). The lack of resumption of menses may be an indication of an underlying comorbidity of EDs/DE or represent athlete noncompliance in the treatment program. The use of athlete treatment contracts and removal from sport participation may be required (Mountjoy et al., 2015, 2018).

Athletes presenting with severe EDs who are medically unstable with a cardiac arrhythmia (e.g., bradycardia); electrolyte imbalance; or hypotension should receive intensive in-patient treatment. Modification to the treatment plan may be required to address comorbid psychopathologies associated with EDs (Sansone \& Sansone, 2007).

\section{Conclusion}

Low energy availability and related clinical conditions are of great concern in athletics, particularly among male and female athletes in middle- and long-distance running and jumping events. However, more studies of the prevalence in sprint, jumping, and multievents 
are needed. Weight loss may occur in the short-term, but long-term LEA negatively affects both health and performance. Therefore, maintaining optimal EA is important for long-term health and performance, while shorter periods of subclinical EA may be required to reach optimal physique goals, especially close to the competition season. Any effort by an athlete to intentionally manipulate EA to achieve a specific physique for sport requires medical supervision including use of sports dietitian to ensure minimum adverse health outcomes during periods of LEA involving periodizing energy and fuel availability around key training sessions and an adequate protein intake. Screening and education with focus on nutrition to maintain optimal EA are important for early intervention and management.

\section{Novelty and Practical Application Statement}

The prevalence of LEA and related clinical conditions is high among male and female middle- and long-distance athletes but also exists in female sprinters with an increased risk of impaired health and performance. Young athletes should be discouraged to manipulate body weight, and sports dietitians counseling adult athletes who need to lose weight should ensure safe and effective weight loss followed by reestablishing optimal EA and weight stability.

\section{Acknowledgments}

The manuscript preparation was undertaken by A.K. Melin, I.A. Heikura, A. Tenforde, and M. Mountjoy. All authors approved the final version of the paper. None of the authors has any potential conflicts of interest.

\section{References}

Barrack, M.T., Fredericson, M., Tenforde, A.S., \& Nattiv, A. (2017). Evidence of a cumulative effect for risk factors predicting low bone mass among male adolescent athletes. British Journal of Sports Medicine, 51(3), 200-205. PubMed ID: 29461218 doi:10.1136/ bjsports-2016-096698

Barrack, M.T., Rauh, M.J., Barkai, H., \& Nichols, J.F. (2008). Dietary restraint and low bone mass in female adolescent endurance. American Journal of Clinical Nutrition, 87(1), 36-43. PubMed ID: 18175735 doi:10.1093/ajcn/87.1.36

Becker, C.B., McDaniel, L., Bull, S., Powell, M., \& McIntyre, K. (2012). Can we reduce eating disorder risk factors in female college athletes? A randomized exploratory investigation of two peer-led interventions. Body Image, 9(1), 31-42. PubMed ID: 22019502 doi:10.1016/j. bodyim.2011.09.005

Bennell, K.L., Malcolm, S.A., Khan, K.M., Thomas, S.A., Reid, S.J., Brukner, P.D., . . . Wark, J.D. (1997). Bone mass and bone turnover in power athletes, endurance athletes, and controls: A 12-month longitudinal study. Bone, 20(5), 477-484. PubMed ID: 9145246 doi:10. 1016/S8756-3282(97)00026-4

Burke, L., Jeukendrup, A., Jones, A., Bosch, A., \& Mooses, M. (2019). IAAF nutrition consensus: Nutrition for long distance events. International Journal of Sport Nutrition and Exercise Metabolism,29(2). doi:10.1123/ijsnem.2019-0004

Burke, L.M., Close, G.L., Lundy, B., Mooses, M., Morton, J.P., \& Tenforde, A.S. (2018). Relative energy deficiency in sport in male athletes: A commentary on its presentation among selected groups of male athletes. International Journal of Sport Nutrition and Exercise Metabolism, 28(4), 364-374. doi:10.1123/ijsnem. 2018-0182

Burke, L.M., Lundy, B., Fahrenholtz, I.L., \& Melin, A.K. (2018c). Pitfalls of conducting and interpreting estimates of energy availability in freeliving athletes. International Journal of Sport Nutrition and Exercise Metabolism, 28(4), 350-363. doi:10.1123/ijsnem.2018-0142

Burke, L.M., Ross, M.L., Garvican-Lewis, L.A., Welvaert, M., Heikura, I.A., Forbes, S.G., . . Hawley, J.A. (2017). Low carbohydrate, high fat diet impairs exercise economy and negates the performance benefit from intensified training in elite race walkers. The Journal of Physiology, 595(9), 2785-2807. PubMed ID: 28012184 doi:10.1113/JP273230

Cialdella-Kam, L., Guebels, C.P., Maddalozzo, G.F., \& Manore, M.M. (2014). Dietary intervention restored menses in female athletes with exercise-associated menstrual dysfunction with limited impact on bone and muscle health. Nutrients, 6(8), 3018-3039. PubMed ID: 25090245 doi:10.3390/nu6083018

Cobb, K.L., Bachrach, L.K., Sowers, M., Nieves, J., Greendale, G.A., Kent, K.K., Brown, B.W., . . Kelsey, J.L. (2007). The effect of oral contraceptives on bone mass and stress fractures in female runners. Medicine \& Science in Sports \& Exercise, 39(9), 1464-1473. PubMed ID: 17805075 doi:10.1249/mss.0b013e318074e532

Day, J., Wengreen, H., Heath, E., \& Brown, K. (2015). Prevalence of low energy availability in collegiate female runners and implementation of nutrition education intervention. Sports Nutrition and Therapy, 1, 1. doi:10.4172/ 2473-6449.1000101

De Souza, M.J., Nattiv, A., Joy, E., Misra, M., Williams, N.I., Mallinson, R.J., . . . Matheson, G. (2014). 2014 female athlete triad coalition consensus statement on treatment and return to play of the female athlete triad: 1st International conference held in San Francisco, California, May 2012 and 2nd International conference held in Indianapolis, Indiana, May 2013. British Journal of Sports Medicine, 48(4), 289. PubMed ID: 24463911 doi:10.1136/bjsports-2013-093218

Drew, M.K., Vlahovich, N., Hughes, D., Appaneal, R., Peterson, K., Burke, L., . . Waddington, G. (2017). A multifactorial evaluation of illness risk factors in athletes preparing for the Summer Olympic games. Journal of Science and Medicine in Sport, 20(8), 745-750. PubMed ID: 28385561 doi:10.1016/j.jsams.2017.02.010

Elliott-Sale, K.J., Tenforde, A.S., Parziale, A.L., Holzman, B., \& Ackerman, K.E. (2018). Endocrine effects of relative energy deficiency in sport. International Journal of Sport Nutrition and Exercise Metabolism, 28(4), 335-349. PubMed ID: 30008240 doi:10.1123/ ijsnem.2018-0127

Fahrenholtz, I.L., Sjödin, A., Benardot, D., Tornberg, Å.B., Skouby, S., Faber, J., . . Melin, A.K. (2018). Within-day energy deficiency and reproductive function in female endurance athletes. Scandinavian Journal of Medicine \& Science in Sports, 28(3), 1139-1146. PubMed ID: 29205517 doi:10.1111/sms.13030

Folscher, L.L., Grant, C.C., Fletcher, L., \& Janse van Rensberg, D.C. (2015). Ultra-marathon athletes at risk for the female athlete triad. Sports Medicine-Open, 1(1), 29. PubMed ID: 30481829 doi:10. 1186/s40798-015-0027-7

Garthe, I., Raastad, T., Refsnes, P.E., Koivisto, A., \& Sundgot-Borgen, J. (2011). Effect of two different weight-loss rates on body composition and strength and power-related performance in elite athletes. International Journal of Sport Nutrition and Exercise Metabolism, 21(2), 97-104. PubMed ID: 21558571 doi:10.1123/ijsnem.21.2.97

Gibbs, J.C., Williams, N.I., Scheid, J.L., Toombs, R.J., \& De Souza, M.J. (2011). The association of a high drive for thinness with energy deficiency and severe menstrual disturbances: Confirmation in a large population of exercising women. International Journal of Sport Nutrition and Exercise Metabolism, 21(4), 280-290. PubMed ID: 21813911 doi:10.1123/ijsnem.21.4.280 
Giel, K.E., Hermann-Werner, A., Mayer, J., Diehl, K., Schneider, S., Thiel, A., \& Zipfel, S. (2016). Eating disorder pathology in elite adolescent athletes. International Journal of Eating Disorders, 49(6), 553-562. PubMed ID: 26876906 doi:10.1002/eat.22511

Gordon, C.M., Ackerman, K.E., Berga, S.L., Kaplan, J.R., Mastorakos, G., Misra, M., . . . Warren, M.P. (2017). Functional hypothalamic amenorrhea: An endocrine society clinical practice guideline. The Journal of Clinical Endocrinology \& Metabolism, 102(5), 14131439. PubMed ID: 28368518 doi:10.1210/jc.2017-00131

Hackney, A.C., \& Lane, A.R. (2018). Low testosterone in male endurancetrained distance runners: Impact of years in training. Hormones, 17(1), 137-139. PubMed ID: 29858867 doi:10.1007/s42000-0180010-Z

Hackney, A.C., Lane, A.R., Register-Mihalik, J., \& O’leary, C.B. (2017). Endurance exercise training and male sexual libido. Medicine \& Science in Sports \& Exercise, 49(7), 1383-1388. PubMed ID: 28195945 doi:10.1249/MSS.0000000000001235

Hausenblas, H.A., \& McNally, K.D. (2004). Eating disorder prevalence and symptoms for track and field athletes and nonathletes. Journal of Applied Sport Psychology, 16(3), 274-286. doi:10. 1080/10413200490485630

Hector, A.J., \& Phillips, S.M. (2018). Protein recommendations for weight loss in elite athletes: A focus on body composition and performance. International Journal of Sport Nutrition and Exercise Metabolism, 28(2), 170-177. PubMed ID: 29182451 doi:10.1123/ijsnem. 2017-0273

Heikura, I.A., Uusitalo, A.L.T., Stellingwerff, T., Bergland, D., Mero, A.A., \& Burke, L.M. (2018). Low energy availability is difficult to assess but outcomes have large impact on bone injury rates in elite distance athletes. International Journal of Sport Nutrition and Exercise Metabolism, 28(4), 403-411. PubMed ID: 29252050 doi:10. 1123/ijsnem.2017-0313

Hinton, P.S., \& Kubas, K.L. (2005). Psychosocial correlates of disordered eating in female collegiate athletes: Validation of the ATHLETE questionnaire. Journal of American College Health, 54(3), 149-156. PubMed ID: 16335314 doi:10.3200/JACH.54.3.149-156

Hoch, A.Z., Pajewski, N.M., Moraski, L., Carrera, G.F., Wilson, C.R., Hoffmann, R.G., . . . Gutterman, D.D. (2009). Prevalence of the female athlete triad in high school athletes and sedentary students. Clinical Journal of Sport Medicine, 19(5), 421-428. PubMed ID: 19741317 doi:10.1097/JSM.0b013e3181b8c136

Huovinen, H.T., Hulmi, J.J., Isolehto, J., Kyrolöläinen, H., Puurtinen, R., Karila, T., . . . Mero, A.A. (2015). Body composition and power performance improved after weight reduction in male athletes without hampering hormonal balance. Journal of Strength and Conditioning Research, 29(1), 29-36. PubMed ID: 25028999 doi:10.1519/JSC. 0000000000000619

Ihle, R., \& Loucks, A.B. (2004). Dose-response relationships between energy availability and bone turnover in young exercising women. Journal of Bone and Mineral Research, 19(8), 1231-1240. PubMed ID: 15231009 doi:10.1359/JBMR.040410

Ikedo, A., Ishibashi, A., Matsumiya, S., Kaizaki, A., Ebi, K., \& Fujita, S. (2016). Comparison of site-specific bone mineral densities between endurance runners and sprinters in adolescent women. Nutrients, 8(12), 781. doi:10.3390/nu8120781

Koehler, K., Achtzehn, S., Braun, H., Mester, J., \& Schaenzer, W. (2013). Comparison of self-reported energy availability and metabolic hormones to assess adequacy of dietary energy intake in young elite athletes. Applied Physiology, Nutrition, and Metabolism, 38(7), 725733. PubMed ID: 23980730 doi:10.1139/apnm-2012-0373

Koehler, K., Hoerner, N.R., Gibbs, J.C., Zinner, C., Braun, H., De Souza, M.J., \& Schaenzer, W. (2016). Low energy availability in exercising men is associated with reduced leptin and insulin but not with changes in other metabolic hormones. Journal of Sports Sciences, 34(20), 1921-1929. PubMed ID: 26852783 doi:10.1080/02640414.2016. 1142109

Laughlin, G.A., \& Yen, S.S. (1996). Nutritional and endocrinemetabolic aberrations in amenorrheic athletes. The Journal of Clinical Endocrinology \& Metabolism, 81(12), 4301-4309. PubMed ID: 8954031

Ljungqvist, A., Jenoure, P.J., Engebretsen, L., Alonso, J.M., Bahr, R., Clough, A.F., . . . Dubi, C. (2009). The International Olympic Committee (IOC) consensus statement on periodic health evaluation of elite athletes, March 2009. Clinical Journal of Sport Medicine, 19(5), 347-365. PubMed ID: 30475245 doi:10.1097/JSM. 0b013e3181b7332c

Loucks, A.B. (2014). Energy balance and energy availability. In R.J. Maughan (Ed.), The encyclopaedia of sports medicine: An IOC medical commission publication (1st ed., pp. 72-87). New York, NY; John Wiley \& Sons.

Loucks, A.B., \& Thuma, J.R. (2003). Luteinizing hormone pulsatility is disrupted at a threshold of energy availability in regularly menstruating women. The Journal of Clinical Endocrinology \& Metabolism, 88(1), 297-311. PubMed ID: 12519869 doi:10.1210/ jc.2002-020369

Loucks, A.B., \& Verdun, M. (1998). Slow restoration of LH pulsatility by refeeding in energetically disrupted women. American Journal of Physiology-Regulatory, Integrative and Comparative Physiology, 275(4), R1218-R1226. doi:10.1152/ajpregu.1998.275. 4.R1218

Maïmoun, L., Coste, O., Puech, A.M., Peruchon, E., Jaussent, A., Paris, F., .. Mariano-Goulart, D. (2008). No negative impact of reduced leptin secretion on bone metabolism in male decathletes. European Journal of Applied Physiology, 102(3), 343-351. doi:10.1007/s00421-0070592-7

Marcus, R., Cann, C., Madvig, P., Minkoff, J., Goddard, M., Bayer, M., . . . Genant, H. (1985). Menstrual function and bone mass in elite women distance runners. Endocrine and metabolic features. Annual Internal Medicine, 102(2), 158-163. doi:10.7326/0003-4819-102-2-158

Martinsen, M., Bahr, R., Børresen, R., Holme, I., Pensgaard, A.M., \& Sundgor-Borgen, J. (2014a). Preventing eating disorders among young elite athletes. Medicine \& Science in Sports \& Exercise, 46(3), 435-447. PubMed ID: 24549033 doi:10.1249/MSS. 0b013e3182a702fc

McNulty, K.Y., Adams, C.H., Anderson, J.M., \& Affenito, S.G. (2001). Development and validation of a screening tool to identify eating disorders in female athletes. Journal of the American Dietetic Association, 101(8), 886-892. PubMed ID: 11501862 doi:10.1016/ S0002-8223(01)00218-8

Melin, A., Tornberg, Å.B., Skouby, S., Faber, J., Ritz, C., Sjödin, A., \& Sundgot-Borgen, J. (2014). The LEAF questionnaire: A screening tool for the identification of female athletes at risk for the female athlete triad. British Journal of Sports Medicine, 48(7), 540-545. PubMed ID: 24563388 doi:10.1136/bjsports-2013-093240

Melin, A., Tornberg, Å.B., Skouby, S., Møller, S.S., Faber, J., SundgotBorgen, J., \& Sjödin, A. (2016). Low-energy density and high fiber intake are dietary concerns in female endurance athletes. Scandinavian Journal of Medicine \& Science in Sports, 26(9), 1060-1071. PubMed ID: 26148242 doi:10.1111/sms.12516

Melin, A., Tornberg, Å.B., Skouby, S., Møller, S.S., Sundgot-Borgen, J., Faber, J., . . S Sjödin, A. (2015). Energy availability and the female athlete triad in elite endurance athletes. Scandinavian Journal of Medicine \& Science in Sports, 25(5), 610-622. PubMed ID: 24888644 doi:10.1111/sms.12261 
Mooses, M., \& Hackney, A.C. (2017). Anthropometrics and body composition in East African runners: Potential impact on performance. International Journal of Sports Physiology and Performance, 12(4), 422-430. PubMed ID: 27631418 doi:10.1123/ijspp.20160408

Mountjoy, M., Sundgot-Borgen, J., Burke, L., Carter, S., Constantini, N., Lebrun, C., . . . Ackerman, K. (2015). The IOC relative energy deficiency in sport clinical assessment tool (RED-S CAT). British Journal of Sports Medicine, 49(21), 1354. PubMed ID: 26764434 doi:10.1136/bjsports-2015-094873

Mountjoy, M., Sundgot-Borgen, J.K., Burke, L.M., Ackerman, K.E., Blauwet, C., Constantini, N., . . . Budgett, R. (2018). IOC consensus statement on relative energy deficiency in sport (RED-S): 2018 update. British Journal of Sports Medicine, 52(11), 687-697. PubMed ID: 29773536 doi:10.1136/bjsports-2018-099193

Muia, E.N., Wright, H.H., Onywera, V.O., \& Kuria, E.N. (2016). Adolescent elite Kenyan runners are at risk for energy deficiency, menstrual dysfunction and disordered eating. Journal of Sports Sciences, 34(7), 598-606. PubMed ID: 26153433 doi:10.1080/ 02640414.2015.1065340

Nattiv, A., Kennedy, G., Barrack, M.T., Abdelkerim, A., Goolsby, M.A., Arends, J.C., \& Seeger, L.L. (2013). Correlation of MRI grading of bone stress injuries with clinical risk factors and return to play: A 5-year prospective study in collegiate track and field athletes. American Journal of Sports Medicine, 41(8), 1930-1941. PubMed ID: 23825184 doi:10.1177/0363546513490645

Nattiv, A., Loucks, A.B., Manore, M., Sanborn, C.F., Sundgot-Borgen, J., \& Warren, M.P. (2007). The female athlete triad. Medicine \& Science in Sports \& Exercise, 39(10), 1867-1882. doi:10.1249/mss. 0b013e318149f111

Pettersson, U., Stålnacke, B.M., Ahlénius, G.M., Henriksson-Larsén, K., \& Lorentzon, R. (1999). Low bone mass density at multiple skeletal sites, including the appendicular skeleton in amenorrheic runners. Calcified Tissue International, 64(2), 117-125. PubMed ID: 9914318 doi:10.1007/s002239900589

Pollock, N., Grogan, C., Perry, M., Pedlar, C., Cooke, K., Morrissey, D., \& Dimitriou, L. (2010). Bone-mineral density and other features of the female athlete triad in elite endurance runners: A longitudinal and cross-sectional observational study. International Journal of Sport Nutrition and Exercise Metabolism, 20(5), 418-426. PubMed ID: 20975110 doi:10.1123/ijsnem.20.5.418

Rickenlund, A., Eriksson, M.J., Schenck-Gustafsson, K., \& Hirschberg, A.L. (2005). Amenorrhea in female athletes is associated with endothelial dysfunction and unfavorable lipid profile. The Journal of Clinical Endocrinology \& Metabolism, 90(3), 1354-1359. PubMed ID: 15572426 doi:10.1210/jc.2004-1286

Sansone, R.A., \& Sansone, L. (2007). Eating disorders and psychiatric comorbidity: Prevalence and treatment modifications. In P.P. Yager J (Ed.), Clinical manual of eating disorders (pp. 79-112). Washington, DC: American Psychiatric Publishing Inc.

Shimizu, K., Suzuki, N., Nakamura, M., Aizawa, K., Imai, T., Suzuki, S., . . . Akama, T. (2012). Mucosal immune function comparison between amenorrheic and eumenorrheic distance runners. Journal of Strength and Conditioning Research, 26(5), 1402-1406. PubMed ID: 22516912 doi:10.1519/JSC.0b013e31822e7a6c

Slater, G., Sygo, J., \& Jorgensen, M. (2019). IAAF nutrition consensus: Nutrition for sprints. International Journal of Sport Nutrition and Exercise Metabolism,29(2). doi:10.1123/ijsnem.2018-0273

Stellingwerff, T. (2018). Case-study: Body composition periodization in an Olympic-level female middle-distance runner over a 9-year career. International Journal of Sport Nutrition and Exercise Metabolism, 28(4), 428-433. doi:10.1123/ijsnem.2017-0312
Stellingwerff, T., Whitfield, J., \& Bovim, I. (2019). IAAF nutrition consensus: Nutrition for middle distance athletes. International Journal of Sport Nutrition and Exercise Metabolism,29(2). doi:10 .1123/ijsnem.2018-0241

Sundfør, T.M., Svendsen, M., \& Tonstad, S. (2018). Effect of intermittent versus continuous energy restriction on weight loss, maintenance and cardiometabolic risk: A randomized 1-year trial. Nutrition, Metabolism \& Cardiovascular Diseases, 28(7), 698-706. doi:10.1016/j .numecd.2018.03.009

Sundgot-Borgen, J., \& Torstveit, M.K. (2004). Prevalence of eating disorders in elite athletes is higher than in the general population. Clinical Journal of Sport Medicine, 14(1), 25-32. doi:10.1097/ 00042752-200401000-00005

Sygo, J., Coates, A.M., Sesbreno, E., Mountjoy, M.L., \& Burr, J.F. (2018). Prevalence of indicators of low energy availability in elite female sprinters. International Journal of Sport Nutrition and Exercise Metabolism, 14, 1-22.

Sygo, J., Kendig, A., Killer, S., \& Stellingwerff, T. (2019). IAAF nutrition consensus: Nutrition for jumps, throws, combined events. International Journal of Sport Nutrition and Exercise Metabolism,29(2). doi:10.1123/ijsnem.2018-0272

Tam, N., Santos-Concejero, J., Tucker, R., Lamberts, R.P., \& Micklesfield, L.K. (2018). Bone health in elite Kenyan runners. Journal of Sports Sciences, 36(4), 456-461. PubMed ID: 28406358

Tenforde, A.S., Carlson, J.L., Chang, A., Sainani, K.L., Shultz, R., Kim, J.H., . . Fredericson, M. (2017). Association of the female athlete triad risk assessment stratification to the development of bone stress injuries in collegiate athletes. The American Journal of Sports Medicine, 45(2), 302-310. PubMed ID: 28038316 doi:10.1177/ 0363546516676262

Tenforde, A.S., \& Fredericson, M. (2011). Influence of sports participation on bone health in the young athlete: A review of the literature. $P M \& R, 3,861-867$.

Tenforde, A.S., Fredericson, M., Sayres, L.C., Cutti, P., \& Sainani, K.L. (2015). Identifying sex-specific risk factors for low bone mineral density in adolescent runners. The American Journal of Sports Medicine, 43(6), 1494-1504. PubMed ID: 25748470 doi:10.1177/ 0363546515572142

Tenforde, A.S., Sayres, L.C., McCurdy, M.L., Collado, H., Sainani, K.L., $\&$ Fredericson, M. (2011). Overuse injuries in high school runners: Lifetime prevalence and prevention strategies. $P M \& R, 3(2), 125-$ 131; quiz 131. PubMed ID: 30472246 doi:10.1016/j.pmrj.2010. 09.009

Tenforde, A.S., Sayres, L.C., McCurdy, M.L., Sainani, K.L., \& Fredericson, M. (2013). Identifying sex-specific risk factors for stress fractures in adolescent runners. Medicine \& Science in Sports \& Exercise, 45(10), 1843-1851. doi:10.1249/MSS.0b013e3182963d75

Thompson, J., Manore, M.M., \& Skinner, J.S. (1993). Resting metabolic rate and thermic effect of a meal in low- and adequate-energy intake male endurance athletes. International Journal of Sport Nutrition, 3(2), 194-206. PubMed ID: 8508196 doi:10.1123/ijsn.3.2.194

Tipton, K.D. (2015). Nutritional support for exercise-induced injuries. Sports Medicine, 45(1), 93-104. doi:10.1007/s40279-0150398-4

Tornberg, Å.B., Melin, A., Koivula, F.M., Johansson, A., Skouby, S., Faber, J., \& Sjödin, A. (2017). Reduced neuromuscular performance in amenorrheic elite endurance athletes. Medicine \& Science in Sports \& Exercise, 49(12), 2478-2485. PubMed ID: 28723842 doi:10.1249/ MSS.0000000000001383

Torstveit, M.K., Fahrenholtz, I., Stenqvist, T.B., Sylta, Ø., \& Melin, A. (2018). Within-day energy deficiency and metabolic perturbation in male endurance athletes. International Journal of Sport Nutrition 
and Exercise Metabolism, 28(4), 419-427. PubMed ID: 29405793 doi:10.1123/ijsnem.2017-0337

Torstveit, M.K., Rosenvinge, J.H., \& Sundgot-Borgen, J. (2008). Prevalence of eating disorders and the predictive power of risk models in female elite athletes: A controlled study. Scandinavian Journal of Medicine \& Science in Sports, 18(1), 108-118. PubMed ID: 17490455 doi:10.1111/j.1600-0838.2007.00657.x

Trexler, E.T., Smith-Ryan, A.E., \& Norton, L.E. (2014). Metabolic adaptation to weight loss: Implications for the athlete. Journal of the International Society of Sports Nutrition, 11(1), 7. PubMed ID: 24571926 doi:10.1186/1550-2783-11-7

Turton, R., Goodwin, H., \& Meyer, C. (2017). Athletic identity, compulsive exercise and eating psychopathology in long-distance runners. Eating Behaviors, 26, 129-132. PubMed ID: 28325645 doi:10.1016/j. eatbeh.2017.03.001
Van Heest, J., Rodgers, C.D., Mahoney, C.E., \& De Souza, M.J. (2014). Ovarian suppression impairs sport performance in junior elite female swimmers. Medicine \& Science in Sports \& Exercise, 46(1), 156-166. doi:10.1249/MSS.0b013e3182a32b72

Whittington, J., Schoen, E., Labounty, L.L., Hamdy, R., Ramsey, M.W., Stone, M.E., . . . Stone, M.H. (2009). Bone mineral density and content of collegiate throwers: Influence of maximum strength. The Journal of Sports Medicine and Physical Fitness, 49(4), 464-473. PubMed ID: 20087308

Williams, N.I., Leidy, H.J., Hill, B.R., Lieberman, J.L., Legro, R.S., \& De Souza, M.J.D. (2015). Magnitude of daily energy deficit predicts frequency but not severity of menstrual disturbances associated with exercise and caloric restriction. American Journal of Physiology_Endocrinology and Metabolism, 308(1), E29-E39. 